\title{
Integrative learning for practicing adaptive resource management
}

\author{
Craig A. McLoughlin ${ }^{1}$ and Martin C. Thoms ${ }^{1}$
}

\begin{abstract}
Adaptive resource management is a learning-by-doing approach to natural resource management. Its effective practice involves the activation, completion, and regeneration of the "adaptive management cycle" while working toward achieving a flexible set of collaboratively identified objectives. This iterative process requires application of single-, double-, and triple-loop learning, to strategically modify inputs, outputs, assumptions, and hypotheses linked to improving policies, management strategies, and actions, along with transforming governance. Obtaining an appropriate balance between these three modes of learning has been difficult to achieve in practice and building capacity in this area can be achieved through an emphasis on reflexive learning, by employing adaptive feedback systems. A heuristic reflexive learning framework for adaptive resource management is presented in this manuscript. It is built on the conceptual pillars of the following: stakeholder driven adaptive feedback systems; strategic adaptive management (SAM); and hierarchy theory. The SAM Reflexive Learning Framework (SRLF) emphasizes the types, roles, and transfer of information within a reflexive learning context. Its adaptive feedback systems enhance the facilitation of single-, double-, and triple-loop learning. Focus on the reflexive learning process is further fostered by streamlining objectives within and across all governance levels; incorporating multiple interlinked adaptive management cycles; having learning as an ongoing, nested process; recognizing when and where to employ the three-modes of learning; distinguishing initiating conditions for this learning; and contemplating practitioner mandates for this learning across governance levels. The SRLF is a key enabler for implementing the "adaptive management cycle," and thereby translating the theory of adaptive resource management into practice. It promotes the heuristics of adaptive management within a cohesive framework and its deployment guides adaptive resource management within and beyond typical single-loop learning, across all governance levels.
\end{abstract}

Key Words: Adaptive feedbacks, assessment, reflection; adaptive management cycle; objectives, targets, thresholds of potential concern; reflexive, single-, double-, triple-loop learning

\section{INTRODUCTION}

Adaptive resource management (ARM) is a learning-by-doing approach to managing natural resources (Allan and Stankey 2009, Walker and Salt 2012, Fabricius and Cundill 2014). It is heuristic in nature with continual updating. The practice of ARM involves an "adaptive management cycle" (Greig et al. 2013, Pratt Miles 2013) consisting of a series of actions, characterized by feedback loops, with the deliberate intent of achieving a set of goals; through the modification and refinement of hypotheses, objectives, outputs/outcomes, and of management actions (Edwards 2002, Stankey et al. 2005). This iterative process is supported by strategic monitoring and feedbacks from the outcome of any decisions (Jiggins and Röling 2002, Allan and Stankey 2009). Thus, the adaptive management cycle is a process based on incremental, experiential learning. However, the effective translation of ARM theory into practice is relatively elusive (Susskind et al. 2012, Rist et al. 2013a, Scarlett 2013, Westgate 2013, Williams and Brown 2014). ARM has been described as confusing (Rist et al. 2013b), and protracted periods of transition in natural resource management exacerbate this confusion. In water resource management, for example, the theory of sustainable water resource management is relatively more advanced than its practice and capacities (skills, knowledge, and competencies) required to implement actual integrated and adaptive water management regimes (Pahl-Wostl 2008, PahlWostl et al. 2011a). Nonetheless, traditional command-andcontrol styles of natural resource exploitation need to be replaced by ARM to respond effectively and efficiently to ensure sustainable management in complex, uncertain, and changing environments (Rogers et al. 2000, Walker and Salt 2012).
The adaptive management cycle has three components: activation, completion, and regeneration. Effectively applying these components and promoting the linkages between them is critical for effective ARM practice. The probability of successfully implementing this adaptive management cycle is greatly enhanced via three different modes of learning (Pahl-Wostl et al. 2013, Fabricius and Cundill 2014). This encompasses processes of "the doing" (single-loop), "changing practice" (double-loop), and "altering governance arrangements" (triple-loop), which is based on increasing time-scales for change (Pahl-Wostl 2009). The challenge for applying this collective three-mode learning is attaining an appropriate balance between the single-loop and double-loop learning modes and therefore avoiding the trap of "learning for the sake of learning" (Fabricius and Cundill 2014). In particular, the triple-loop mode of learning is important because if the structural contexts within resource governance regimes are too rigid, this can impede the "reframing" requirements of double-loop learning (Pahl-Wostl 2009). Critical enabling conditions associated with applying this collective threemode learning have been considered within the broader context of ARM. Adaptive governance arrangements have been explored by Folke et al. (2005), Gunderson and Light (2006), Pahl-Wostl (2009), and Herrfahrdt-Pahle (2013), while Fazey and Schultz (2009) define the requirements for learning centered organizations. In addition, the importance of social learning processes have been emphasized by Mostert et al. (2007), Ison and Watson (2007), Pahl-Wostl (2009), and Cundill et al. (2012), and Rogers et al. (2013) highlight a complexity "frame of reference" for adaptive decision making. In practice, applying three-mode learning has been difficult to achieve (Pahl-Wostl et 
al. 2013, Fabricius and Cundill 2014) despite much research and identification of enabling conditions. As a result, many natural resource management regimes remain trapped in the single-loop mode of learning, by maintaining and improving established routines (Pahl-Wostl 2009, Pahl-Wostl et al.2011b).

Achieving an appropriate balance between single-, double-, and triple-loop learning (termed here as three-mode learning) within an ARM context is challenging. Reflexive learning can assist in building capacity in this area (Pahl-Wostl et al. 2007a, Pollard and du Toit 2007, Fabricius and Cundill 2014). Reflexive learning is "learning from action," with the deliberate intent to enhance the practice of management (Kolb 1984). According to Pollard and du Toit (2007), reflexive learning can be portrayed as a "feedback loop," whereby actions are manipulated and/or modified via feedback from the context within which they were executed. Effective feedback systems have adaptive assessment and reflection routines (Biggs et al. 2011a), which require debate between all stakeholders. Strategic transfers of information aid this process within and between flexible, informal, and adaptive network systems (Pahl-Wostl 2009). Fundamentally, reflexive learning processes execute feedbacks for more immediate responses in ARM, but also for the adaptive assessment and reflection routines. It is these responses and routines that facilitate three-mode learning. ARM is an evolutionary process with many contemporary programs in the early pioneering phase (Fabricius and Cundill 2014), and because reflexive learning receives little explicit attention in adaptive management cycle frameworks/ models, application of three-mode learning is often compromised. Thus, a greater emphasis and focus on reflexive learning is required to facilitate an appropriate balance between and use of single-, double-, and triple-loop learning. Achieving this balance would increase the feasibility of reflexive learning thus supporting and enhancing the ARM adaptive management cycle.

Our aim is to outline a heuristic framework for the practice of ARM, heuristic because it serves to promote further learning or discovery, and a framework that enables identification of common problems and solutions as well as appropriate variables and their descriptors (Jabareen 2009). A heuristic framework is a strategy that guides the search for information and in doing so allows for modifications to facilitate solutions. They are seen as being indispensable for integrative thinking and solving problems especially when logic and probability theory cannot provide solutions (Pickett et al. 1999). We focus on building a foundation of reflexive learning to facilitate an appropriate balance within three-mode learning that promotes the activation, completion, and regeneration components of the ARM adaptive management cycle to achieve goals.

\section{THREE-MODE LEARNING}

The three-mode learning process advocated here refines the concept of triple-loop learning, which influences governing variables in relation to initial assumptions and values (Pahl-Wostl 2009). Originating from management theory (Hargrove 2002) triple-loop learning builds on double-loop learning developed by Argyris and Schon (1978), increasing the time scales for change by considering the different management and governance levels that provide direction and stability in social contexts (Pahl-Wostl 2009). It differs from single-loop learning, which results in the incremental advances from action strategies, without questioning underlying assumptions (Pahl-Wostl 2009). Single-loop learning involves a continuation of, with concurrent improvements to, established practices and routines, in targeting the achievement of goals. In comparison, double-loop learning refers to a change in the actual frame of reference and includes a revisitation of the initial underlying assumptions of any action (Pahl-Wostl 2009). Social learning processes, building trust through cooperation and buy-in between stakeholders for example, are vital in double-loop learning (Pahl-Wostl 2009). The reframing process commonly occurs within stakeholder networks characterizing the resource governance regime and improvements are achieved by experimenting with innovative approaches. Stakeholders involved in double-loop learning normally explore reframing in the context of structural constrains of governance systems, such as regulatory frameworks. Change in structural constraints is however, associated with triple-loop learning (Pahl-Wostl 2009). Tripleloop learning includes a transforming of the factors that determine the frame of reference, transformation of the entire governance regime itself (Pahl-Wostl 2009). This style of transformation necessitates an acknowledgment that paradigms and structural constraints inhibit effective reframing of resource governance and management practices. Hence, triple-loop learning implies a paradigm shift as well as changes in the norms and values underlying the processes of governance (Pahl-Wostl 2009). Here we view the three-mode learning process as incorporating single-loop, double-loop, and triple-loop learning.

Four criteria are required to establish a learning cycle that can support double- and/or triple-loop learning (Pahl-Wostl 2009, Pahl-Wostl et al. 2013). First, there must be an informal network of participants who conduct regular meetings. The rules and arrangements (for example, who is included, the operational requirements, leadership) of the network must not be formally imposed. Second, the mandate of this network must be open ended, and the results not formally binding straightaway. Third, the network of participants must deal with specific problems, and is open to experimentation involving different approaches (allowing for innovation). Fourth, the network has joint and shared practices (communities of practice, sensu Wenger 1998) and tangible products to generate an identity for itself, including a history and a body of shared knowledge that is different to that of individuals within the network. Notably, there is increased ability for self-organization, innovation, and creative thinking if the social networks are more autonomous and informal.

\section{CONCEPTUAL PILLARS FOR BUILDING REFLEXIVE LEARNING}

Three conceptual pillars central to reflexive learning, are recognized in the SRLF.

\section{Stakeholder driven adaptive feedback systems}

The production of knowledge through policy and management actions, its dissemination to all stakeholders via feedback systems, and its actual use, are integral parts of adaptive management (Stankey et al. 2005). Both explicit (objective facts) and tacit knowledge (experiential) are important in the learning process of adaptive management. Individuals acquire their own tacit knowledge about the world, which can only be shared by common practice. Tacit knowledge is valuable because it contributes to innovation in adaptive management systems (Pahl-Wostl et al. 
2007a). The ability of stakeholder networks to use new information within shared social learning experiences is critical because it creates opportunities to facilitate collective action that emerges from the process of incorporating and synthesizing new knowledge (Pahl-Wostl et al. 2007a, b). However, processes of sharing of new information and derived knowledge must be cognizant of the quality and types of communication systems in networks rather than just undertaking a synthesis of this information and knowledge. This can be aided by considering the appropriateness of institutional settings for processing information and subsequent knowledge (Pahl-Wostl et al. 2007a). For example, using tools such as computer simulation programs ensure complex problems are explained in understandable ways to multiple stakeholders. Adaptive management requires that all knowledge is enacted, whether it is skill-based or attitudinal, as a result from shared experiences (Pahl-Wostl et al. 2007a, Rogers et al. 2013).

The practice of ARM involves sharing experiences, by improving the flow of information and ultimately better communication via feedbacks (see Stankey et al. 2005). Along with the more immediate responses in ARM, deployments of feedback loops are required to drive the core routines of adaptive assessment and reflection. Assessment differs from reflection, with the former being to evaluate or estimate the nature, quality, ability, extent, or significance of something, whereas reflection is seen more as a calm, lengthy, intent-driven consideration (Biggs et al. 2011a). Both are important within ARM, and when adaptive assessment and reflection operate together they generate a shared understanding among stakeholders (Biggs et al. 2011a). Implementing adaptive assessment and reflection routines help shape deliberations under adaptive management (Biggs et al. 2011a), which is also an important basis for facilitating threemode learning under ARM.

\section{Strategic adaptive management (SAM)}

SAM builds on ARM by strengthening collaboration between stakeholders and enhancing feedback systems. The SAM framework provides the reflexive learning structure for the SRLF.

\section{The SAM framework}

The SAM framework consists of three adaptive phases (Pollard and du Toit 2007, Roux and Foxcroft 2011, Kingsford and Biggs 2012). First, the Adaptive Planning Phase commences with the development of a vision, formulated on the basis of an understanding about context and values of the system under management. The vision is achieved, ensuring stakeholder consensus, using the criteria of VSTEEP (values; social; technical; environmental; economic; political), through a process of identifying vital attributes of the system with their key determinants. The vision and vital attributes of the system informs the setting of objectives, the outcome of which is a cascading set of objectives and subobjectives known as the Objectives Hierarchy. The vision statement at the pinnacle of the Objectives Hierarchy is broken down into higher-level objectives that are essentially value-laden statements about the "desired future state" of the system under management. The systematic break down of these higher-level objectives into subobjectives, with increasing focus and rigor, culminates in developing Thresholds of Potential Concern (TPC). These are the explicit, measureable end-points that guide management and are used for assessing the achievement of the interlinked higher-level objectives. The Objectives Hierarchy is central to SAM focusing the research and management agenda within a set of agreed stakeholder objectives (van Wilgen and Biggs 2011), thus facilitating and guiding the Adaptive Implementation Phase of the SAM process.

The Adaptive Implementation Phase has several key components. These include scoping of management options to meet objectives, planning and operationalization of selected options, as well as developing and implementing monitoring to provide the necessary information for use within the Adaptive Evaluation Phase. Learning and adapting over time within the Adaptive Evaluation Phase occurs throughout the SAM process via a series of feedback loops (see Roux and Foxcroft 2011). In doing so it determines how well management interventions have worked in line with the objectives and ultimately the vision. Overall, the Adaptive Planning Phase of SAM sets up the Adaptive Implementation Phase (van Wilgen and Biggs 2011) and this is pivotal for executing feedback processes of the Adaptive Evaluation Phase. Experience of implementing SAM in various settings, has shown that progress is typically quicker within the Adaptive Planning Phase because it is relatively easier to get agreement on a desired future state across a range of value systems, than it is to implement the measures required to achieve this desired future state (van Wilgen and Biggs 2011). Hence, application of TPCs is critical for operationalizing the Adaptive Implementation Phase of SAM, and concurrently the Adaptive Evaluation Phase.

\section{Thresholds of potential concern and feedbacks}

Within the SAM framework, TPCs are typically "decision thresholds," seen as an optimization of both ecological (scientific/ model-based) and utility (value/objectives-based) thresholds (see Fig. 1; Martin et al. 2009), rather than specific predicted ecosystem thresholds (Biggs et al. 2011b). The process of constructing TPCs identifies all pertinent drivers within a system as well as measurable response indicators of change related to these drivers. They also recognize the natural variability of these response indicators by incorporating upper and lower levels (thresholds) of acceptable change. Often, there are many TPCs required (and developed) when the SAM process commences, but the idea is to narrow this set down to have as few TPCs as possible, to monitor against for guiding management. This idea epitomizes a resilience style of thinking, and is based on the "requisite simplicity" principle, i.e., as simple as possible, but not too simple (Walker and Salt 2012). This is important because resources are typically scarce under adaptive management programs.

Implementing TPCs in SAM requires an existing understanding of the dynamics of the system under management. This understanding does not have to be complete. Development of TPCs lies along a continuum, from empirically well or fairly well understood, through an intermediate position informed by expert opinion, to an intelligent early guesswork or from a conceptual understanding of the system (Biggs et al. 2011b). When determining TPCs, there is often uncertainty as to whether a real threshold even exists, and if so where it lies exactly. Thus, TPC developers often become hesitant because they expect TPCs to deliver this certainty (Biggs et al. 2011b). Further hesitation is generated with an expectation that the process is linear, or believed 
Fig. 1. Development of Thresholds of Potential Concern (TPCs) in strategic adaptive management (SAM) is an inductive approach to adaptive management. TPCs are hypotheses of acceptable change (in an indicator of interest) and open to challenge. Therefore, to implement the TPCs in SAM one only requires an existing understanding, however incomplete at the time, of the dynamics within a system under management. TPCs are often developed as "first generation TPCs," which then require revision over time as new knowledge becomes available, and/or based on changing human values. Although TPCs often presage predicted ecological thresholds (scientific/model based understanding in ecology), they often integrate with utility thresholds (values, objectives-based understanding associated with human ideals). Typically, developing TPCs in SAM involves an optimization of ecological and utility type thresholds, becoming decision thresholds. Adapted from Martin et al. (2009). Ecological Applications: A publication of the Ecological Society of America. Reproduced with permission of Ecological Society of America, in the format republish in a journal/magazine via Copyright Clearance Center.

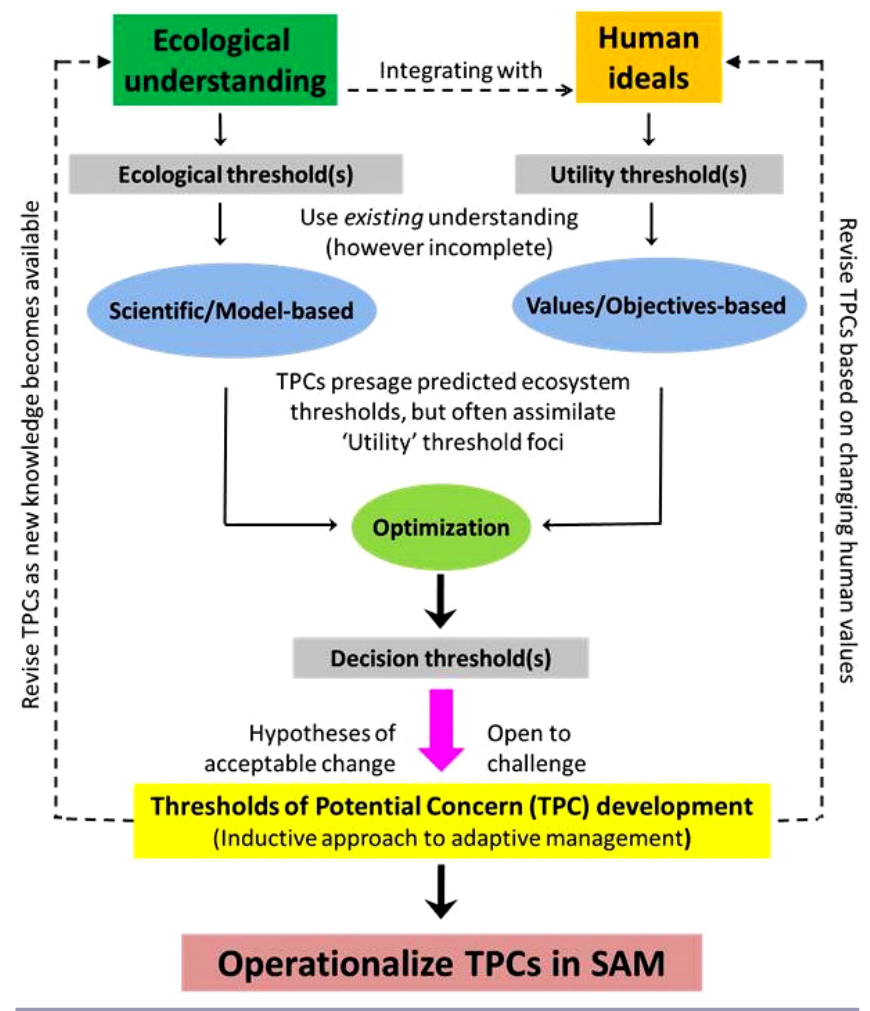

not to have a clear threshold. Although detection of abrupt change is useful, within the TPC process it makes little practical difference if some TPCs happen to describe a linear process (Biggs et al. 2011b). Thus, TPCs are viewed as hypotheses of acceptable change and open to challenge and refinement, forming an inductive approach to adaptive management (Rogers and Biggs 1999, Biggs and Rogers 2003; see Fig. 1).
By using best available information to determine TPCs, SAM monitors trends and then mandates reflection on collaboratively identified goals before mutually agreed action is taken (Pollard et al. 2011). Collectively, TPCs define the measurable component of the "desired future state" under SAM. This desired future state falls within the "tent boundary," formed by the collective of TPCs (or "targets" if system state is already outside the tent boundary; cf. Biggs et al. 2011b). The notion of TPCs under SAM is a "redflag" concept, because TPCs are intended as an early warning system prior to the actual threshold (often theoretical) boundaries being reached. If and when TPCs are exceeded (known from monitoring, and/or modelling), this sets in motion a stakeholder driven process of investigation as to the reasons why, and possible management action necessary, or TPC revision. Importantly, without a monitoring program to allow auditing of the TPCs, the SAM process remains academic and unimplementable, because evaluating the outcomes of proposed management actions cannot be achieved (McLoughlin et al. 2011a). Monitoring can be resource expensive hence monitoring requirements of TPCs must be practicable, fast, affordable, and effective. As scientific understanding improves, and/or human values change, TPCs should be refined, if and when appropriate (see Fig. 1; McLoughlin et al. 2011b). However, management intervention may be required to avoid the system moving out of the tent boundary, or if the system is already outside of this boundary then for rehabilitation back. Therefore, development, use, and auditing of TPCs in SAM are important for providing feedback into research and management within an iterative, adaptive process. This functions to keep management strategically adaptive, rather than reactive (Rogers and Biggs 1999). Although the TPC concept, within the context of SAM, evolved within an ecological domain its principles have wider application especially in the economic and social domains (see Swemmer and Taljaard 2011).

\section{Hierarchy theory}

Hierarchy theory allows for the decomposition of a system into levels of organization, thereby forming a hierarchical structure (Ahl and Allen 1996). Each level of organization or holon is a separate entity whose character is constrained by those holons immediately above and influenced by those emerging from the level immediately below. Thus, levels within a hierarchy are not strictly independent of each other (Parsons and Thoms 2007). Hierarchical systems have three main properties. First, each level of organization has its own distinct spatial and temporal scales, so that higher levels have larger spatial and longer temporal scales and those at lower levels have smaller spatial and shorter temporal scales. Second, the frequency or rate of operation differs between each level of organization so that higher levels in a hierarchy have lower frequencies of behavior compared to lower levels. Third, higher levels of organization constrain lower levels because their larger entities have slower rates of processing information or frequency rates and therefore react more slowly than lower levels. Conversely, lower levels of organization are faster but smaller entities providing initiating conditions to upper levels. Lower levels within an organization influence those at higher levels through their faster rate flow of information and emerging properties. Hierarchy theory is applicable to systems with natural hierarchical structures and is appropriate for use in natural, 
public, and societal systems problems (Dollar et al. 2007), dealing with complexity.

Hierarchical concepts are common in many disciplines of study, with each organizing their subject of study into distinct hierarchical levels of organization. Fundamental to ecological understanding is the familiar hierarchical levels of organism, species, community, and ecosystem (Barrett et al. 1997). Although levels of organization are not scales (Petersen and Parker 1998), they operate in characteristic spatial and temporal domains and are used to stratify components within any system. For example, physiology and behavior are generally studied at the level of the individual, whereas species richness and diversity are studied at the community level and energy and nutrient fluxes are studied at the ecosystem level. Scale defines the physical dimension of an entity and Quinn and Keogh (2002) characterize scale in terms of grain and extent. Grain refers to the smallest spatial or temporal interval in an observation set and has also been referred as the smallest scale or pattern to which an organism may respond (O'Neill et al. 1989) or the smallest scale of influence of an ecosystem disturbance or process driver (Rogers 2003). Extent is the total area or duration over which observations are made, the largest pattern to which an organism responds (that is, the habitats used by a fish or the time over which a given habitat is used), or the largest scale at which a disturbance or process driver exerts influence on the system. Therefore, grain and extent define the upper and lower limits of resolution in the description of a level of organization of an ecosystem. Assigning a scale to a hierarchical level of organization provides contextual meaning and more importantly it determines the variables and units of measure that can be associated with each level of a particular hierarchy.

Hierarchical translations within interdisciplinary areas of study are becoming more common (Thoms and Parsons 2002). The frameworks of Thoms and Parsons (2002) and Dollar et al. (2007) provide examples of how individual disciplinary (or subsystem) hierarchical structures use scale as the currency for linking between disciplines. Recognition of spatial and temporal scales inherent to the levels of organization of a disciplinary hierarchy makes integration of multiple subsystems possible (Dollar et al. 2007). Integration of scales allows researchers and managers to ask appropriate questions through recognition that there are causal linkages across different disciplines or organizations. There are four steps in the application of the frameworks put forward by Thoms and Parsons (2002) and Dollar et al. (2007). The first step requires identification of various subsystems and the second focuses on describing the relevant levels of organization that characterize the different subsystems in the context of the issue/ problem being addressed. The third step involves the identification of appropriate scales and variables within the different organizational levels and step four describes the process interactions between appropriately identified subsystem components. Overall, hierarchy theory provides a valuable mechanism for investigators to disentangle system complexity, improving our understanding and thinking through complex problems. Hierarchy theory is important in building the SRLF because it allows the "multiscale" requisites of reflexive learning across all governance levels that are coupled with three-mode learning.

\section{THE SAM REFLEXIVE LEARNING FRAMEWORK}

The SRLF has a nested hierarchical structure with three levels of organization within the ARM governance (Fig. 2). Adaptive water resource management in South Africa for example, may recognize the national boundary as the SRLF Level-1, and nested within this are a number of water management areas, the SRLF Level-2, of which there are 19 demarcated water management areas. Nested within each water management area are individual river catchments for ARM implementation at SRLF Level-3. The SRLF is designed to facilitate three-mode learning within each level of organization as well as providing the linkages between these levels. It is also dependent on relative rather than absolute scales (Kotliar and Wiens 1990) of governance thereby making the SRLF applicable for any hierarchical structure, from global, national, or basin levels of organization and from regional to local levels of organization. At any given spatial scale of application, more than three levels of ARM governance may be utilized through the nominated scale, if deemed necessary.

\section{SAM reflexive learning framework structure and function}

A strategic trait of SRLF is the development of a multilayered set of objectives that cascades through all three SRLF governance levels (see Fig. 2). Learning adaptively, toward achieving these scaled objectives is the main focus of SRLF. Objectives setting commences with a visioning process at Level-1, resulting in development of an overall Vision statement. The relevant content derived in the Vision statement is decomposed into a series of higher-level objectives specific to Level-1 that are differentiated according to themes (Fig. 2). Themes depend on the Vision statement and may include Environment, Economic, and Community/Social. There are a set of "policy targets" for each theme, for example, increase biodiversity in freshwater systems of South Africa, emanating from the higher-objectives and these depict the end-point goals at Level-1 (Fig. 2). Within the SRLF, policy targets are then decomposed into a set of subobjectives at Level-2 that are characterized by increasing focus and rigor. Specification of "management targets," for example, restore percentages of river habitat types in the Inkomati Water Management Area, represents the end-point goals of the subobjectives at Level-2; and this is also done for each theme (Fig. 2). Subsequently, management targets are further decomposed into the subobjectives at Level-3. At this level of organization they culminate in the Thresholds of Potential Concern (TPC), for example, bedrock-influenced river habitat type coverage is 20 percent or less in rivers of the Crocodile River Catchment, as the explicit end-point goals of the subobjectives at this level of organization (Fig. 2). This hierarchical approach to the setting of objectives within the SRLF has the advantage of providing practitioners, operating at different SRLF levels, the opportunity to pinpoint pertinent end-point goals and the appropriate scales in which to implement ARM processes that are feasible to achieve these end-point goals, and associated objectives.

\section{The SRLF entity}

The SRLF entity is defined as a group of interlinked SAM cycles; one for each theme, Environment, Economic, and Community/ Social (Fig. 2). SRLF entities occur at each level of organization and work collectively toward achieving their determined objectives at the particular SRLF level. With the hierarchical structure of SRLF there will be many small-scale Level-3 SRLF entities that nest under a parent Level-2 SRLF entity, and the 
Fig. 2. The Strategic adaptive management (SAM) Reflexive Learning Framework (SRLF) exhibits a nested, hierarchical structure, across three levels of governance. A SRLF entity comprises interlinked SAM cycles for the Environment, Economic, and Community/Social themes. Typically, there are many Level-3 entities nested within fewer parent Level-2 entities, and these all nest within the single Level-1 entity. The Vision statement, derived at Level-1, is broken down into the Higher-objectives (per theme) at Level-1. These Higher-objectives culminate in Policy Targets at Level-1. Policy Targets cascade down into more detailed Level-2 Subobjectives, culminating in Management Targets at Level-2. Management Targets cascade down into finer detailed Level-3 Subobjectives, culminating in Thresholds of Potential Concern (TPCs) at Level-3. "Top-down" processes in SRLF include policy influences that constrain the types of Level-2 management approaches allowed. In turn, management approaches selected control the types of Level-3 actions required. The main "bottom-up" process involves learning. Learning is initiated primarily during the TPC feedback processes occurring within Level-3 entities. Information/knowledge is collated up to parent Level-2 entities to inform the Management Targets; similarly information/knowledge is collated up to the parent Level-1 entity to inform Policy Targets. Functional attributes pertaining to SRLF entities vary dependent on governance level. This is demonstrated along three axes: the spatial scale of influence and size of constraints imposed on SRLF practitioners and stakeholders; the rate of stakeholder interaction, including development of critical innovations for change; and the time-scale for change, related to the degree of flexibility and self-organization inherent in the stakeholder forums. Additionally, practitioner mandates are defined across the governance levels, represented conceptually by hierarchy "grain" and "extent." This differentiates practitioner responsibilities and accountabilities (spatially) for applying SAM cycle processes, per level of SRLF.

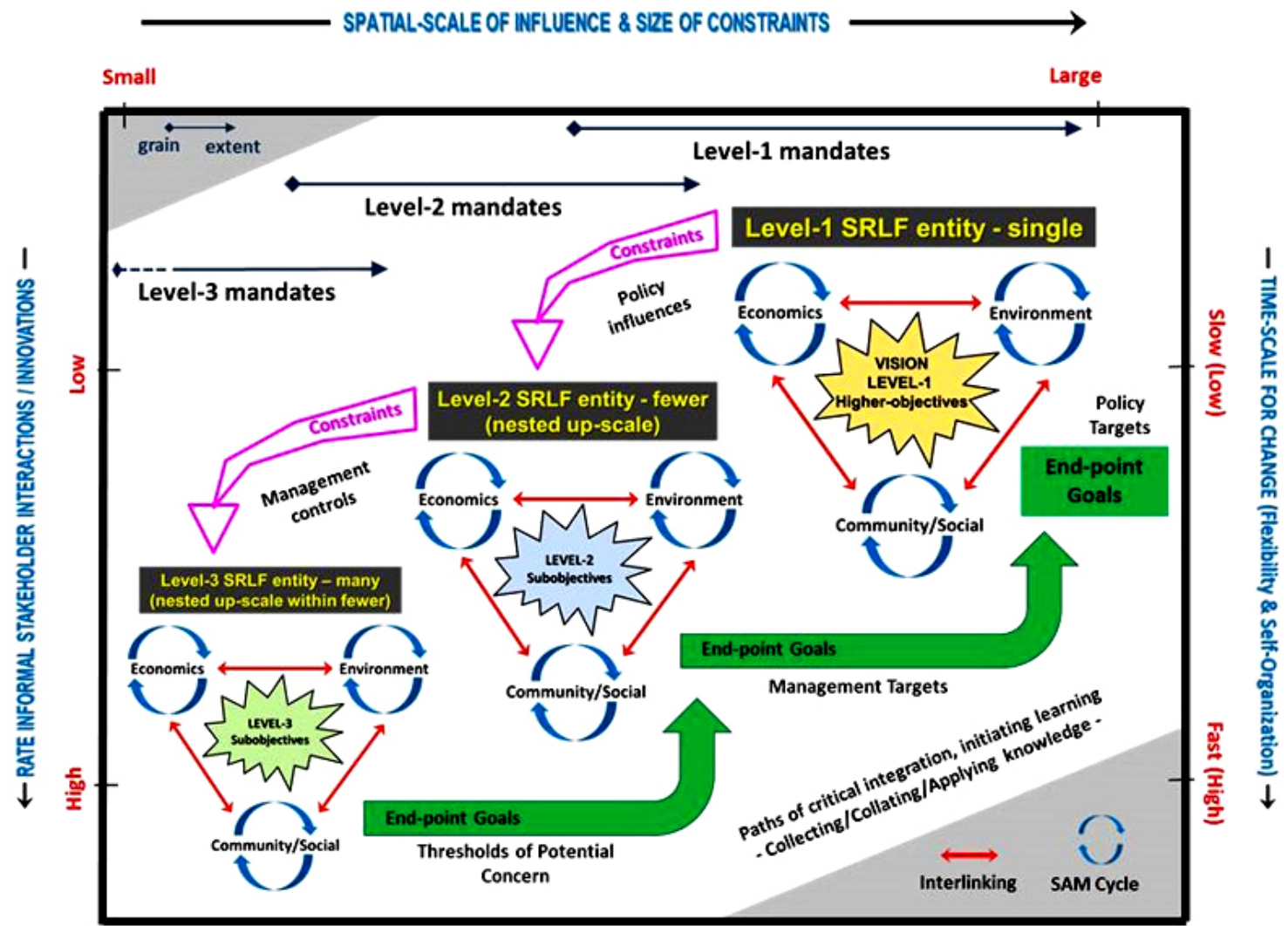

fewer number of Level-2 SRLF entities all nest under one largescale Level-1 SRLF entity (Fig. 2). Information flows, through adaptive feedbacks facilitating three-mode learning potentials, must be executed within all SAM cycles to activate, complete, and then regenerate the SAM cycles within SRLF entities. SAM cycles contained within the SRLF entities are required to be interlinked (see Fig. 2) because it is widely accepted that ecological, economic, and social systems are inextricably bound (Folke et al. 2005,
Walker and Salt 2012). Thus, when considering intervention strategies to meet the agreed objectives and end-point goals for each theme the intervention paths chosen for a particular SAM cycle must be formulated in conjunction with any potential impacts on SAM cycles of the other themes. Therefore, to meet the full range of objectives at each level of organization in the SRLF it is crucial that SAM cycles comprising a SRLF entity are both interdependent and are operating in tandem with each other 
(Fig. 2). Overall, these SAM cycles give effect to the practice of ARM under SRLF.

\section{SRLF entity: attributes across SRLF levels}

SRLF entities vary across the three SRLF levels of organization, defined along three axes according to specific functional attributes (Fig. 2). First, the Spatial-scale of Influence and Size of Constraints, the Level-1 SRLF entity, has the largest jurisdiction and influence over ARM implementation. However, the largest constraints are imposed on implementing ARM at Level-1, relative to the other levels. For example, more rigid governance arrangements will negatively impact change potentials at Level-1. Second, the Rate of Informal Stakeholder Interactions / Innovations, the scale of informal relationships and stakeholder interactions, is highest within Level-3 SRLF entities, diminishing through Level-2 to Level-1 SRLF entities. Thus, elevated potentials for learning occur at Level-3, compared to the two higher SRLF levels, because learning is fostered in the less formal structures (Pahl-Wostl et al. 2013) where social learning is nurtured (Pahl-Wostl 2009). Third, the Time-scale for Change (Flexibility and Self-Organization), faster scales of adaptability, occur within Level-3 SRLF entities. This results from quicker stakeholder response times due to higher flexibility and selforganization of ARM stakeholders at Level-3, enhancing learning potentials (Pahl-Wostl et al. 2013). Thus, there is increasing potential for ARM realization, because of escalating amounts of flexibility in governance arrangements associated with Level-2 going into Level-3 SRLF entities, which is more conducive to change. A decreasing scale of flexibility in governance arrangements, occurring within SRLF entities of Level-2 up to the Level-1 entity, produces slower response times in these entities, thus increasingly longer time steps are required for change.

ARM practitioner "grain" and "extent" across SRLF levels ARM practitioners, for example, agricultural and environmental consortia, and civil society, operating at the SRLF Level-1 assume the largest scale of geographical influence (extent) over ARM implementation (Fig. 2). These practitioners deal primarily with policy development and implementation, which is linked to meeting the predetermined policy targets. They oversee adaptive processes occurring within the Level-1 SRLF entity and in order to evaluate policy targets they must also administer and collate information emanating from all SRLF entities at Level-2. Thus, Level-2 is effectively the grain for these ARM practitioners, who have no direct mandate at lower levels (Fig. 2). ARM practitioners operating at Level-2, for example, catchment management agencies, and Level-3, for example, catchment forums including local authorities, communities, and researchers, have diminishing scales of geographical influence (extent) under ARM (Fig. 2). Level-2 ARM practitioners are primarily responsible for determining and achieving management targets linked to higherlevel policy, by implementing suitable management approaches and they must oversee adaptive processes occurring within the Level-2 SRLF entities. To evaluate management targets they must also administer and collate information emanating from all nested SRLF entities at Level-3. Thus, Level-3 is effectively the grain for these ARM practitioners, who have no direct mandate at lower sublevels (Fig. 2). Level-3 ARM practitioners are responsible for action on-the-ground, to achieve the TPCs linked to higher level management, and must implement detailed adaptive management processes within the Level-3 SRLF entities, but at pertinent nested sublevels too. Thus, detailed sub-Level-3 areas become the grain for these ARM practitioners (Fig. 2), who may not distinguish any further ARM mandate, although smaller areas may exist, under SRLF.

\section{Vertical linkages across SRLF levels}

There is a top-down link in SRLF, and this is molded by societal values that emerge during the visioning process at SRLF Level-1. Policy targets, as the detailed end-point goals at Level-1 shape policies derived at Level-1. Ultimately, this influences and constrains management within nested Level-2 entities because management targets as end-point goals at Level-2 are ultimately derivatives of specific policy targets determined, and policies impact the types of Level-2 management approaches allowed (Fig. 2). Management targets at SRLF Level-2 determine types of TPCs required at Level-3, and management approaches selected at Level-2 then control and constrain actions pertinent for the nested Level-3 entities (Fig. 2). There is also a bottom-up link that ensures a critical path characterized by integration and learning (Fig. 2). Here, information and derived knowledge from Level-3 SRLF entities, where learning potentials are highest, acquired within the TPC process, are collated at higher levels of organization through feedback loops into parent SRLF Level-2 entities. This occurs in order for consolidation and learning at this level to meet the management targets, and is done so in all Level-2 SRLF entities consolidating into the one Level-1 SRLF entity to inform policy implementation outcomes. This bottom-up process facilitates decision making and learning across all SRLF levels to meet the complete hierarchy of objectives in SRLF, and ultimately the derived Vision at Level-1.

The generic vertical structure of SRLF exhibits a nested pattern of SAM cycles distributed across the three levels of organization, and these levels differentiate the types of interventions required to meet different end-point goal types (see Fig. 3). For pragmatic implementation considerations, this nested distribution of SAM cycles is applied separately to each theme, Environment, Economic, Community/Social. The Environment theme, for example, has many Level-3 SAM cycles nested within and overseen by fewer Level-2 SAM cycles (Fig. 3). Similarly, these Level-2 SAM cycles are nested within and are overseen by the single Level-1 SAM cycle (Fig. 3). The objectives applicable to the Environment theme are cascaded downward through all levels of the SRLF with increased focus and rigor (Fig. 3), for application within these SAM cycles.

\section{SAM cycle: horizontal structure per SRLF level}

The SAM cycle of the SRLF entity is based on the model developed by McLoughlin et al. (2011a). The SAM cycle is iterative, with a distinct arrangement of adaptive phases and components applied to each theme of the SRLF entity. The SAM cycle horizontal structure is applicable at each level of organization within the SRLF, and consists of two phases: (1) Adaptive Planning, composed of two adaptive components (represented in the black boxes in Fig. 4); the first represents development of the objectives, corresponding to the particular level; the second represents development of the detailed end-point goals culminating at the base of these objectives; and (2) Adaptive Implementation, composed of five adaptive components (represented in the grey boxes in Fig. 4). This includes processes 
Fig. 3. The nested distribution pattern of strategic adaptive management (SAM) cycles across governance Level-1, Level-2, and Level-3 of the SAM Reflexive Learning Framework (SRLF), applicable to each SRLF entity theme (Environment, Economic, and Community/Social). Intervention type, governance level, spread of Objectives, and End-point Goal types are also indicated. Notably, there is increasing focus and rigor of the Objectives from Level-1, through Level-2 into Level-3, characterized by a decrease in societal values and an increase in detail of the end-point goal outcomes. Arrows (blue) between governance levels represent critical vertical feedbacks required in SRLF ("top-down" and "bottom-up").

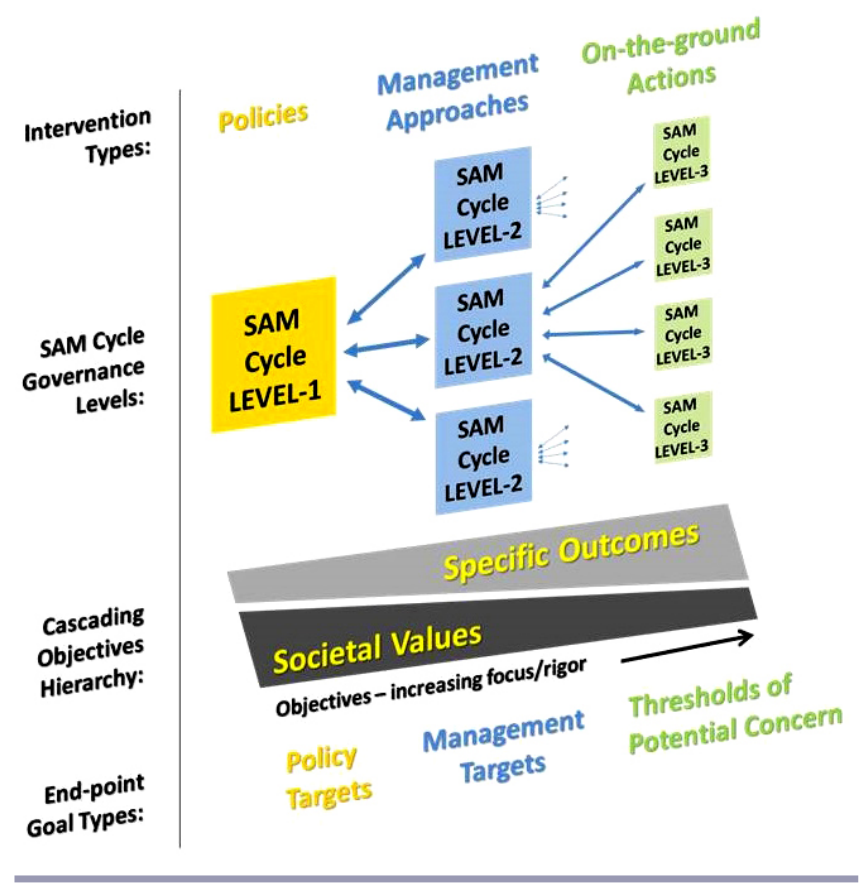

of selecting the best intervention options to meet the developed end-point goals; determining inputs for planning, associated with meeting end-point goals; operationalizing inputs via implementation of the plans; checking adequacy of plan implementation by swift response to operational outputs; assessing suitability of the operational outputs by auditing strategic outcomes, against end-point goals; and testing achievement of the broader objectives applicable at each SRLF level.

The starting position and direction of the SAM cycle is given in Figure 4 and is applicable to subsequent iterations of the SAM cycle. Details relevant to each adaptive component of the Adaptive Planning Phase and Adaptive Implementation Phase of the SAM cycle, across SRLF levels, are given in Table 1. SAM cycle phases and components are standard across all SRLF levels, although key differences are dictated by objective and end-point goal determination at each level. Additionally, the type of intervention to achieve the objectives and end-point goals varies according to the particular SRLF level, for instance policy, management, and action related interventions at Level-1, Level-2, and Level-3, respectively (see Table 1). The adaptive phases and
Fig. 4. The generic horizontal structure of the strategic adaptive management (SAM) cycle used within the SAM Reflexive Learning Framework (SRLF) entities. Two components of the SAM Adaptive Planning Phase and five components of the Adaptive Implementation Phase are given. Determining the Objectives and associated End-point Goals commences the SAM cycle process, in the clock-wise direction. Importantly, in determining "Intervention Options" for one particular theme, there must be cognizance of potential impacts on achieving objectives linked to the other two themes. This generic SAM cycle horizontal structure is used at SRLF Level-1, Level-2, and Level-3 as detailed in Table 1.

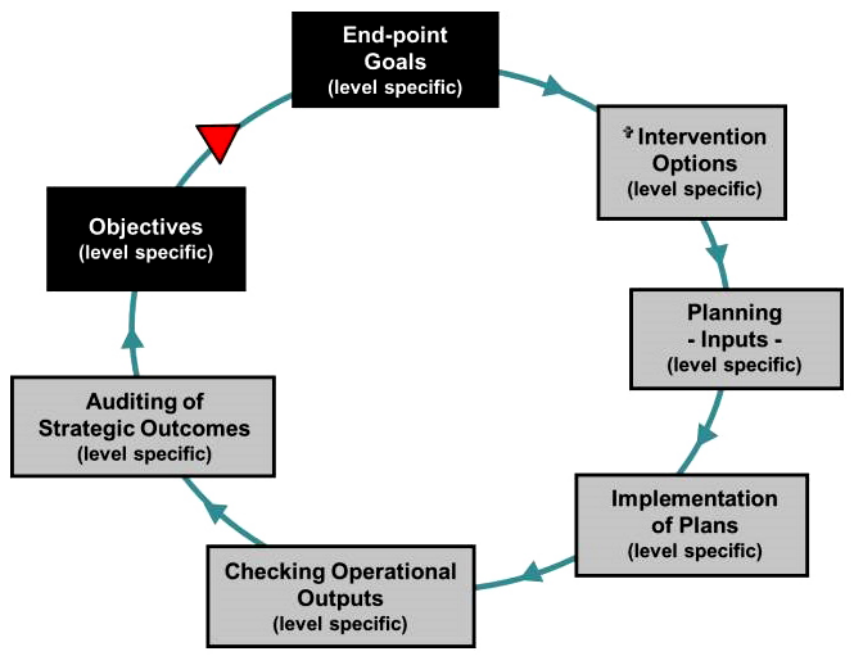

+ Cognizant of potential impacts on achieving Objectives of the other two themes Iteration Starting Position $\quad-$ Adaptive Management Cycle Direction SAM CYCLE PHASES:

Adaptive Planning

Adaptive Implementation

components of the SAM cycle at each SRLF level sanction strategic feedbacks for guiding three-mode learning, by facilitating an appropriate balance between the modes of single-, double-, and triple-loop learning.

\section{SAM cycle feedbacks facilitating three-mode learning}

Horizontal adaptive feedbacks within SRLF levels

There are two kinds of nested learning potentials facilitated by reflexive learning within the generic SAM cycle, namely Adaptive Learning and Transformational Learning (Pahl-Wostl et al. 2013; see Fig. 5). The Adaptive Learning component includes both single- and double-loop learning. There are two grades of feedbacks to facilitate single-loop learning, including "lower" (red, thin/solid arrows) that give rise to the more immediate responses in ARM, to check if the operational inputs are being implemented correctly, that is achieving the intended output results; and "upper" (blue, hashed arrows) that give rise to adaptive assessment routines, auditing strategic outcomes against the end-point goal benchmarks. Feedbacks for double-loop learning (green, dotted arrows) give rise to adaptive reflection 
Table 1. Processes associated with components of the Adaptive Planning and Adaptive Implementation phases of the strategic adaptive management (SAM) cycle used in the SAM Reflexive Learning Framework (SRLF), applicable to SRLF Level-1, Level-2, and Level-3.

\begin{tabular}{|c|c|c|c|c|c|c|}
\hline \multicolumn{2}{|c|}{ Adaptive Planning Phase } & \multicolumn{5}{|c|}{ Adaptive Implementation Phase } \\
\hline Objectives & $\begin{array}{l}\text { End-point } \\
\text { Goals }\end{array}$ & $\begin{array}{l}\text { Intervention } \\
\text { Options }\end{array}$ & $\begin{array}{l}\text { Planning } \\
\text { - Inputs - }\end{array}$ & $\begin{array}{l}\text { Implementation } \\
\text { of Plans }\end{array}$ & $\begin{array}{l}\text { Checking } \\
\text { Operational } \\
\text { Outputs }\end{array}$ & $\begin{array}{c}\text { Auditing of } \\
\text { Strategic } \\
\text { Outcomes }\end{array}$ \\
\hline
\end{tabular}

\begin{tabular}{|c|c|c|}
\hline $\begin{array}{l}\text { Higher- } \\
\text { objectives within } \\
\text { the SAM } \\
\text { Reflexive } \\
\text { Learning } \\
\text { Framework, } \\
\text { emanating from } \\
\text { the overall } \\
\text { Vision } \\
\text { statement. }\end{array}$ & $\begin{array}{l}\text { Policy Targets, as } \\
\text { broader end- } \\
\text { points of the } \\
\text { Level-1 Higher- } \\
\text { objectives. }\end{array}$ & $\begin{array}{l}\text { Best Policies, } \\
\text { expected to allow } \\
\text { for meeting of the } \\
\text { Policy Targets. }\end{array}$ \\
\hline
\end{tabular}

\begin{tabular}{|c|c|c|c|}
\hline $\begin{array}{l}\text { Broad Planning } \\
\text { documents, } \\
\text { incorporating inputs } \\
\text { necessary for } \\
\text { implementation of } \\
\text { Policies across nested } \\
\text { Level-2 entities. }\end{array}$ & $\begin{array}{l}\text { Operationalizing } \\
\text { inputs given in the } \\
\text { planning documents } \\
\text { at Level-1. }\end{array}$ & $\begin{array}{l}\text { Checking } \\
\text { implementation of } \\
\text { Level-1 plans. } \\
\text { Collating } \\
\text { operational } \\
\text { information from } \\
\text { across nested } \\
\text { Level-2 entities. }\end{array}$ & $\begin{array}{l}\text { Collation/synthesis of } \\
\text { all monitoring data/ } \\
\text { information, emanating } \\
\text { from across nested } \\
\text { Level-2 entities, } \\
\text { associated with auditing } \\
\text { against the Policy } \\
\text { Targets. }\end{array}$ \\
\hline
\end{tabular}

Subobjectives, and rigor, points of the Level-2 Subobjectives.
Detailed Subobjectives, well-developed focus, cascaded down from Level-2.
Thresholds of Potential Concern (TPC), as finely detailed, explicit end-points of the Level-3 Subobjectives.

\section{Appropriate Management approaches, expected to allow for meeting of the Management Targets.}

Governance Level-2:

\begin{tabular}{|c|c|c|c|}
\hline $\begin{array}{l}\text { Detailed Planning } \\
\text { documents, } \\
\text { incorporating inputs } \\
\text { necessary for } \\
\text { implementation of } \\
\text { Management } \\
\text { approaches across } \\
\text { nested Level-3 entities. }\end{array}$ & $\begin{array}{l}\text { Operationalizing } \\
\text { inputs given in the } \\
\text { planning documents } \\
\text { at Level-2. }\end{array}$ & $\begin{array}{l}\text { Checking } \\
\text { implementation of } \\
\text { Level-2 plans. } \\
\text { Collating } \\
\text { operational } \\
\text { information from } \\
\text { across nested } \\
\text { Level-3 entities. }\end{array}$ & $\begin{array}{l}\text { Collation/synthesis of } \\
\text { all monitoring data/ } \\
\text { information, emanating } \\
\text { from across nested } \\
\text { Level-3 entities, } \\
\text { associated with auditing } \\
\text { against the } \\
\text { Management Targets. }\end{array}$ \\
\hline
\end{tabular}

Governance Level-3:

Pertinent Actions Highly detailed Planning documents, incorporating inputs necessary for implementation of Actions, within Level-3 entities.

\begin{tabular}{|c|c|c|}
\hline $\begin{array}{l}\text { Operationalizing } \\
\text { inputs given in the } \\
\text { planning documents } \\
\text { at Level-3. }\end{array}$ & $\begin{array}{l}\text { Checking } \\
\text { implementation of } \\
\text { Level-3 plans. } \\
\text { Collating } \\
\text { operational } \\
\text { information from } \\
\text { within Level-3 } \\
\text { entities. }\end{array}$ & $\begin{array}{l}\text { Collation/synthesis of } \\
\text { all monitoring data/ } \\
\text { information, emanating } \\
\text { from within Level-3 } \\
\text { entities, associated with } \\
\text { auditing against the } \\
\text { TPCs. }\end{array}$ \\
\hline
\end{tabular}

routines, which evaluate achievement of the broader objectives within the SAM cycle (with consideration of any surprises), and there is potential for reframing end-point goals and existing planning inputs. Feedbacks for triple-loop learning (pink, thick/ solid arrows) allow adaptive reflection into a holistic review process of all objectives and end-point goals. This reflection and review process promotes Transformational Learning and is combined with a reconsideration of underlying values, for adapting governance systems and the effective regeneration of the SAM cycle.

Three-mode learning within each SAM cycle is an ongoing process, nested over increasing time-scales for change (Table 2). Key attributes and processes particular to the single-, double-, and triple-loop modes of learning are defined in Table 2, for each SRLF level.

Vertical adaptive feedbacks across SRLF levels

For each SRLF theme, Environment, Economic, and Community/Social, collating information from the Level-3 SAM cycles, through parent Level-2 SAM cycles into the Level-1 SAM cycle is essential. This allows for learning, initiated at Level-3, to bridge with policy decisions (vis-à-vis Pahl-Wostl et al. 2013) occurring at SRLF Level-1. Thus, potential to evaluate and link the end-point goals and associated objectives across SRLF levels is expedited, and ultimately with the overall Vision determined at SRLF Level-1.

It must be expected that advancement in ARM will not occur uniformly across governance levels because of disparate rates in realizing critical enabling conditions for three-mode learning. Panarchy theory, with its complex adaptive cycles including the four phases of exploitation, conservation, release, and reorganization (Holling 2001, Gunderson and Holling 2002), has been useful in assessing processes of change across levels of organization within systems (Garmestani et al. 2009). Although not within the scope of this manuscript, integration of these concepts into SRLF development would be beneficial, because further understanding about change, and influences across ARM governance levels, is needed.

\section{DEPLOYING THE SAM REFLEXIVE LEARNING FRAMEWORK}

The SRLF instigates integrative thinking associated with the contemporary problem of translating ARM theory into practice. It achieves this by demonstrating a generic, explicit and pragmatic 
Fig. 5. The learning process is not linear in the Strategic adaptive management (SAM) Reflexive Learning Framework (SRLF). SRLF uses a nested set of generic adaptive feedbacks within each SAM cycle, and this is applied at SRLF Level-1, Level-2, and Level-3 as described in Table 2. These feedbacks occur simultaneously but over increasing time-scales for change, by providing potential for both Adaptive and Transformational learning (vis-à-vis Pahl-Wostl et al. 2013). This is given effect by facilitation of three-mode learning, in relation to meeting Objectives and associated End-point Goals, which allows for activation, completion, and regeneration of the SAM cycle. Specifically, by allowing for more immediate responses to check operational outputs (red, solid arrows); adaptive assessment, to audit strategic outcomes against End-point Goals (blue, hashed arrows); adaptive reflection, to test achievement of the Objectives (considering any surprises; green, dotted arrows); and review, a holistic revision of the Objectives and associated End-point Goals, with transformation of governance arrangements to improve application of the SAM cycle (pink, thick solid arrows). It is important that when reviewing Objectives and associated End-point-Goals for one particular theme, there is cross-reference to the other two themes where pertinent. For comparison, hypothetical time-scales for learning loop types within the SAM cycle, at different governance levels in SRLF, are: Level-1 > 3-5 years (single-loop, lower), 5-8 years (single-loop, upper), 8-10 years (double-loop), and 10-15 years (triple-loop); Level-2 > 1-3 years (single-loop, lower), 3-6 years (single-loop, upper), 6-8 years (double-loop), and 8-10 years (triple-loop); Level-3 > daily/weekly (single-loop, lower), 1-3 years (single-loop, upper), 3-5 years (double-loop), and 5-6 years (triple-loop).

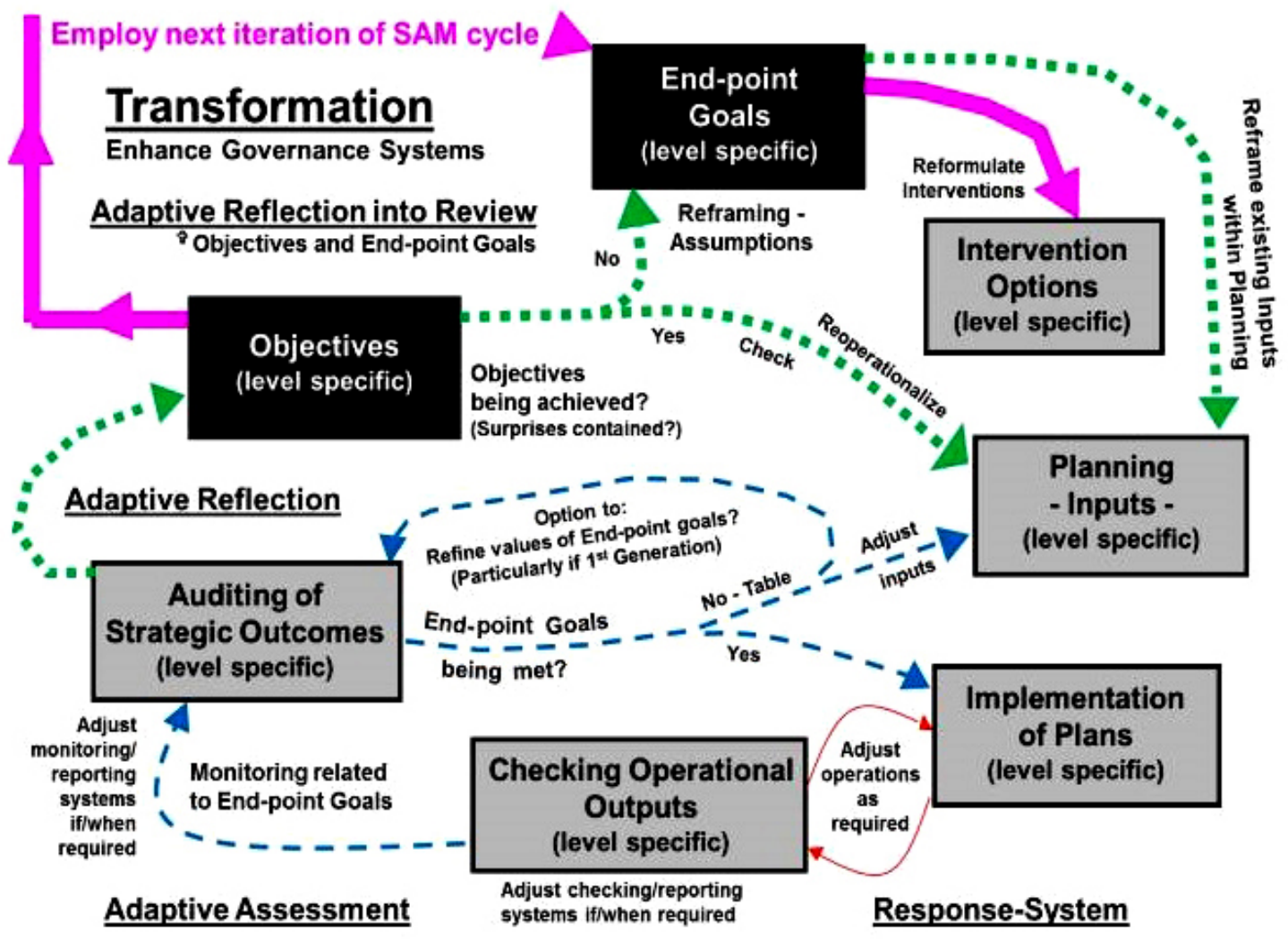

Cross-reference Objectives of the other two themes

\begin{tabular}{|c|c|c|c|c|}
\hline \multirow{3}{*}{$\begin{array}{l}\text { Facilitated nested } \\
\text { learning loop:- }\end{array}$} & \multicolumn{3}{|c|}{ Adaptive Learning } & $\begin{array}{c}\text { Transformational } \\
\text { Learning }\end{array}$ \\
\hline & \multicolumn{2}{|c|}{ Single-Loop } & Double-Loop & Triple-Loop \\
\hline & Lower & Upper & & \\
\hline
\end{tabular}


Table 2. Learning potentials in the Strategic adaptive management (SAM) Reflexive Learning Framework (SRLF). A functional description of the SAM cycle nested feedback system, demonstrating explicitly where and when to implement more immediate responses, adaptive assessment, adaptive reflection, and review with governance transformation. These feedbacks facilitate and guide single-, double-, and triple-loop learning in the SRLF, ultimately for activating, completing, and then regenerating the SAM cycles.

\begin{tabular}{|c|c|c|c|}
\hline \multicolumn{3}{|c|}{ Adaptive Learning Potential } & \multirow{3}{*}{$\begin{array}{c}\text { Transformational Learning } \\
\text { Potential } \\
\text { Triple-loop Learning Facilitation }\end{array}$} \\
\hline \multicolumn{2}{|c|}{ Single-loop Learning Facilitation } & Double-loop Learning Facilitation & \\
\hline Lower Subloop & Upper Subloop & & \\
\hline $\begin{array}{l}\text { Response-System } \\
\text { Feedbacks }\end{array}$ & $\begin{array}{l}\text { Adaptive Assessment } \\
\text { Feedbacks }\end{array}$ & $\begin{array}{l}\text { Adaptive Reflection } \\
\text { Feedbacks }\end{array}$ & $\begin{array}{l}\text { Adaptive Reflection into Review, } \\
\text { with Governance Transformation }\end{array}$ \\
\hline
\end{tabular}

At all governance levels:

Implementation of planning inputs, linked to intervention options selected, must be tested to check if (a) the planning inputs were implemented as intended, and (b) the desired output results did actually occur.

A Response-System is employed during operationalization of the inputs. To adjust operations in a timely way to achieve the intended outputs

Adjustment of checking/reporting systems is done if/when required.
Strategic outcomes are audited against End-point Goals to test if these are being met. If not, then this is tabled. Adjusting existing planning inputs must be considered, and or an option to revise specific values of End-point Goals.

Reimplementation of the adjusted inputs is required.

Adjustment of monitoring/ reporting systems is done if/when required.
Governance Level-1:

Time-interval: Stakeholder meetings every $3-5$ years.

Response-System concerning testing of outputs: Collation of results from nested Level-2 entities, to decide if intended outputs at level- 1 are actually transpiring.

If Level-1 planning inputs are not being implemented as intended, with expected outputs not occurring at Level-1, then adjustment to implementation is required, of the planning inputs at Level-1, to obtain intended output results over the long term.
Time-interval: Stakeholder meetings and workshops every 5-8 years.

Adaptive Assessment within the Level-1 entity auditing strategic outcomes: Collation of monitored results from nested Level-2 entities, to decide if Policy Targets at Level-1 are being met.

Auditing Policy Targets spawns feedbacks for further decision making. If Policy Targets are not met then this is tabled. Decisions required: existing policy planning inputs at Level-1 require adjustment and reimplementation across nested Level-2 entities, and/ or specific target values can be revised (particularly if first generation targets). these targets. revised Policy Targets, with planning inputs.
Auditing of strategic outcomes is not an end in itself. A lengthy intent driven consideration (reflection) of Objectives is necessary.

If these Objectives are not being met, then reframing of End-point Goals is necessary, using acquired knowledge. Occurrence of surprises (i.e., unexpected outcomes) must be evaluated to learn from these events (e.g., a related, but unexpected decline in a species of concern other than the indicator species).

Reframing, involving an in-depth rethinking of planning inputs, is also necessitated. The revised inputs must be implemented to achieve the newly developed Endpoint Goals.

\section{Time-interval: Stakeholder}

Reviewing all Objectives, including End-point Goals is necessitated because human values change over time. New knowledge acquired must also be incorporated back into the SAM cycle process.

Reconsideration of governance at each level is important. This

facilitates institutional arrangement transformation to improve application of the SAM cycle.

Rethinking options for intervention is necessary, in working toward achieving all revised Objectives and related End-point Goals.

Time-interval: Stakeholder workshops every $10-15$ years.

Adaptive Reflection within the Level-1 entity, to decide if higher (more value-laden) Objectives at Level-1 are being achieved. If not, then assumptions associated with Policy Targets require reframing, with potential for redeveloping

Reframing of policy planning inputs is also required based on new knowledge to achieve the implementation of the reframed
Adaptive Reflection within the Level-1 entity, to review the Higher- (value-laden) objectives and Policy Targets.

There is evaluation of existing paradigms, with deliberation of structural context. Involves altering regulatory frameworks (e.g., rules) that may be stalling application of the SAM cycle. Key challenges exist because of prohibitive rigidity of governance systems at Level-1.

With this, the SAM cycle of the Level-1 entity is completed.

Regeneration, allowing for the next iteration of the SAM cycle, commences with reformulation of Policies to meet newly devised Higher-objectives and associated Policy Targets at Level-1. 
Time-interval: Stakeholder meetings every $1-3$ years.

Response-System concerning testing of outputs: Collation of results from nested Level-3 entities, to decide if intended outputs at level-2 are actually transpiring.

If Level-2 planning inputs are not being implemented as intended, with expected outputs not occurring at Level-2, then adjustment to implementation is required, of the planning inputs at Level-2, to obtain intended output results over the medium-term.
Time-interval: Daily, or weekly communication, via email and or phone. Monthly stakeholder meetings, to determine if operations and feedback systems are occurring adequately.

\section{Rapid-Response-System} concerning testing of outputs: Collation of results from nested sites within Level-3 entities, to decide if intended outputs at level-3 are actually transpiring.

If Level-3 planning inputs are not being implemented as intended, with expected outputs not occurring at Level-3, then adjustment to implementation is required, of the planning inputs at Level-3, to obtain intended output results over the short term.

Governance Level-2.

Time-interval: Stakeholder Time-interval: Stakeholder meetings and workshops every 3-6 workshops every 6-8 years. years.

Adaptive Assessment within each

Level-2 entity, auditing strategic outcomes: Collation of monitored results from nested Level-3 entities, to decide if Management Targets are being met.

Auditing Management Targets spawns feedbacks for further decision making. If Management Targets are not met then this is tabled. Decisions required: existing management planning inputs at Level-2 require adjustment and reimplementation across nested Level-3 entities, and or specific target values can be revised (particularly if first generation targets).
Adaptive Reflection within each Level-2 entity, to decide if Subobjectives at Level-2 are being met. If not, then assumptions associated with Management Targets require reframing, with potential for redeveloping these targets.

Reframing of management planning inputs is also required based on new knowledge to achieve the revised Management Targets, with implementation of the reframed planning inputs.

Time-interval: Stakeholder workshops every 8-10 years.

Adaptive Reflection within each Level-2 entity, to review the Subobjectives and Management Targets.

Includes evaluation of current institutional arrangements. Innovations must be identified and promoted, and associated constraints (e.g., lack of decisionmaking delegation) reduced.

Working progressively toward achieving adaptable governance at Level-2 is paramount.

With this, SAM cycles of Level-2 entities are completed.

Regeneration, allowing for the next iteration of the SAM cycle, commences with reformulation of Management approaches to meet newly devised Subobjectives and associated Management Targets at Level-2.

Governance Level-3:

Time-interval: Stakeholder meetings and workshops every 1-3 workshops every 3-5 years. years.

Adaptive Assessment within each Level-3 entity, auditing strategic outcomes: Collation of results from on-the-ground monitoring activities at sites. Thresholds of Potential Concern (TPC), the explicit and measurable end-points, are audited to evaluate if thresholds of specified indicators are exceeded, or not.

TPC rationale and monitoring protocols guide and prioritize monitoring activities at Level-3 sites. TPCs are tabled if or when exceeded, or close to being exceeded thus giving time for adjusting actions to avoid TPC exceedance. TPC reporting formats spawn feedbacks for further decision making, i.e., adjusting existing action planning inputs, and or revising existing thresholds of TPCs (particularly if first generation TPCs).
Adaptive Reflection within each

Level-3 entity, to decide if Subobjectives at Level-3 are being met. If not, then reframing of assumptions (hypotheses and or models) used in TPC development is required, using newly acquired

knowledge. New TPCs may be developed if pertinent TPC challenges have been posed during the period.

Reframing of action planning inputs is also required based on new knowledge to achieve the revised and or new TPCs developed, with implementation of these reframed planning inputs.
Time-interval: Stakeholder workshops every 5-6 years.

Adaptive Reflection within each Level-3 entity, to review the Subobjectives and TPCs.

Includes evaluation of stakeholder network systems. Increasing stakeholder participation is important. Encouragement of key innovations is required, and this is used to transform stakeholder networks into more adaptive networks, promoting flexible and informal interactions.

With this, SAM cycles of Level-3 entities are completed.

Regeneration, allowing for the next iteration of the SAM cycle, commences with reformulation of Actions to meet newly devised Subobjectives and associated TPCs at Level-3. 
reflexive learning schema for facilitating three-mode learning under ARM. Specifically, SRLF promotes an appropriate balance and use of the single-, double-, and triple-loop modes of learning at different governance levels, and this is important for implementing the adaptive management cycle, at each SRLF level. It is acknowledged that deployment of the SRLF will occur in situations where real-world components and processes are already happening within programs of natural resource management. For instance, governance arrangements will be in place and policies determined with various monitoring activities implemented. The idea of SRLF is that is it seen as a pragmatic tool for guiding the practice of ARM. The intention is that its principles be integrated into existing components and processes where pertinent, and this is the key challenge for deploying the SRLF. Examples are, explicitly considering the impact of multilevel governance arrangements for implementing the adaptive management cycle; or the need to reconsider older (entrenched) monitoring systems and formulate new strategic ones, such as at SRLF Level-3 with potential to measure progress against TPCs. Strategic interventions can then be actively tested against a measurable desired future state that has been agreed upon by all stakeholders; because stakeholder involvement is paramount in SRLF, particularly when determining objectives and related end-point goals.

Importantly, SRLF is not the remedy for achieving successful three-mode learning outcomes under ARM, because in realworld situations three-mode learning is dependent on other factors too, for example, stakeholder participation rates and how these stakeholders are engaged; development of learning centered organizations that encourage three-mode learning; fostering critical capacities for social learning, specifically important for double-loop learning; and achieving adaptable governance regimes, which allows for triple-loop learning. Notably, financial and other managerial logistics, including risk, also impact implementation of ARM. Nonetheless, the overarching benefit of applying the SRLF in ARM programs is that it unpacks the reflexive learning process, clearly, to guide practitioners through three-mode learning and implementing the adaptive management cycle. The SRLF improves on existing ARM adaptive management cycle frameworks by focusing, explicitly, on the types, roles, and transfers of information in adaptive feedback systems (reflexive learning) and this is fostered by several key elements:

\section{Streamlining coupled sets of objectives across SRLF levels} Fragmentation of objectives commonly imposes a loss of collective purpose, momentum, and focus associated with implementation of the adaptive management cycle under ARM. This often occurs across different levels of implementation. Under SRLF, the scaled, cascaded set of objectives is the common currency of the ARM venture. These objectives integrate organizational levels in SRLF by permitting a common purpose for ARM, given effect via increasing focus and rigor down SRLF levels. Thus, the objectives determine the rationale for SRLF, but also unite practitioners in their different roles, responsibilities, and mandates.

\section{Incorporation of multiple but interlinking SAM cycles}

It can be overwhelming to conceptualize the what, when, and how-to implement the adaptive management cycle under ARM, because of the wide range of objectives to be met. Under SRLF, this is resolved by separate SAM cycles within individual themes, i.e., Environment, Economic, and Community/Social, or other, thereby making it easier to contemplate specific adaptive processes, for example, goal setting or monitoring, as related to each theme. This promotes learning efficiencies in the task of activating, completing, and then regenerating the SAM cycles. Importantly, thematic SAM cycles within the SRLF must be interlinking, because being cognizant of all intervention strategies is important to achieve the full range of objectives across SRLF themes.

Applying three-mode learning as an ongoing, nested process Nested feedbacks occur over a broad range of time-scales in SRLF, from days/weeks (minimum time-step at SRLF Level-3) to decades (maximum time-step at SRLF Level-1). The evaluation (learning) phase is not depicted as a separate step along the SAM cycle, as is given in many ARM models. Often, these models begin with objectives and problem formulation, which then flow into implementation and monitoring, then an evaluation step implying subsequent feedback back into problem formulation (Gregory et al. 2012, Williams and Brown 2014). This suggests that processes of evaluation occur at discrete intervals toward the end of the adaptive management cycle. Under SRLF, this evaluation step is deliberately excluded from the SAM cycle, because feedback processes for the more immediate responses in ARM, along with adaptive assessment and adaptive reflection are nested and ongoing; this is conveyed explicitly within the SAM cycles (see Fig. 5).

\section{Explicitly recognizing when and where to apply three-mode learning}

In the SRLF, at each governance level, the nested feedbacks for single-loop learning (both lower and upper) are mandatory and ongoing, because these incorporate the actual doing (improving established practices to meet end-point goals) and this is where progress is made within ARM (Fabricius and Cundill 2014). Notably, double-loop learning feedbacks are invoked only if and when required, that is after deeper reflection has examined achievement of the objectives, at each SRLF level. If the objectives are not being met (considering any surprises) then changing practices becomes pertinent. For example, at SRLF Level-3 devising alternate TPCs (end-point goals) via redefining assumptions (hypotheses and models), along with updating monitoring systems and existing planning inputs, may be necessary. Over longer time-scales, triple-loop learning is required, i.e., a holistic review of the objectives based on changing human values, including revision of the end-point goals. A deliberate attempt to adapt governance systems at each particular SRLF level is also required. With this, the SAM cycle (per theme) contained within SRLF entities (across levels) is completed, and set for regeneration by applying all newly available knowledge to achieve a revised hierarchy of objectives.

\section{Distinguishing initiating conditions for three-mode learning and} time-scales for change

Slower response times of entities at higher levels in a hierarchy must be seen as standard practice, not failure. Relative to SRLF Level-3 entities, the longer time frames for change within the SRLF Level-1 entity (and to a lesser degree SRLF Level-2) must be conceded when inferring achievements under SRLF. Hence, 
outcomes for three-mode learning are initially pursued within the Level-3 entities (within constraints from higher levels) because these exhibit quicker learning potentials. Increased capacities for social learning and the development, use, and auditing of TPCs at Level-3 supports this learning. Subsequently, and over longer time-scales, SRLF Level-3 entities influence learning in the upper SRLF levels, via vertical feedbacks.

\section{Explicitly contemplating practitioner mandates across $S R L F$ levels}

Practitioners at lower governance levels often become overwhelmed by higher level factors that constrain processes throughout ARM, thereby stunting their motivation because such factors are out of their direct control. These factors include policy processes, formal and inflexible governance arrangements, exacerbated by diminished capacities for social learning. Meanwhile, practitioners operating at the policy level may not receive satisfactory feedback from the lower levels; becoming bogged down by too much detail. Their capacity to evaluate policy outcomes is, therefore, diminished. Under SRLF, explicitly defining practitioner mandates across SRLF levels is required, to clarify (feasible) implementation roles and responsibilities in the practice of ARM. Here, panarchy theory is useful for furthering understanding.

Four criteria will increase effectiveness of SRLF deployment. First, champions at each SRLF level are required; these operators are the glue that binds the ARM process together, without which it is more likely to fail. Principal champions are those practitioners operating at SRLF Level-2 because their mandates coincide with both SRLF Level-1 and Level-3 practitioner mandates. These practitioners coordinate information flows, vertically across SRLF levels for learning to result throughout SRLF. Second, applying the SRLF is not organization specific, but a collaborative venture comprising all stakeholders, and these stakeholders cover all the themes under SRLF (within one social-ecological and economic system). Here, adaptive network systems are built across all organizational sectors, and these ideally become "communities of practice" (sensu Wenger 1998) that then oversee SRLF deployment. Third, achieving adaptable governance regimes across SRLF levels is expedient, particularly the establishment of polycentric and decentralized governance arrangements. With this, decision-making powers are devolved to the lower SRLF levels, thus SRLF Level-3 practitioners (and at Level-2) exhibit the freedom to oversee and implement their ARM mandates as necessary. Fourth, it is astute to include a research component as part of the objectives strategically developed within SRLF (all levels, for each theme). Research objectives define research priorities associated with implementation of the SAM cycle, broken down into applied and basic research subobjectives. Applied research may be concerned with developing new TPCs at SRLF Level-3 (as these are required). New TPCs are developed using new knowledge emanating from basic research, which has the primary role of soliciting and overseeing research to enhance understanding about systems in ARM.

Overall, the heuristic SRLF serves as an exploratory map for integrative learning in the practice of ARM. This is beneficial because subsequent modifications to the SRLF will provide a measure of progress in integrative thinking (Pickett et al. 1999) associated with this learning.

\section{CONCLUSIONS}

Effective ARM practice requires activation, completion, and then regeneration of the adaptive management cycle, which works toward achieving a flexible set of collaboratively identified objectives. This iterative process, at all governance levels, requires an appropriate balance and use of single-, double-, and tripleloop learning, to strategically modify inputs, outputs, assumptions, and hypotheses linked to improving policies, management approaches and actions, along with transforming governance. The SRLF consolidates essential reflexive learning heuristics of adaptive management explicitly under one framework and its deployment guides ARM purposely within and beyond the single-loop learning, across three governance levels. Hence, the SRLF is a key enabler for implementing the ARM adaptive management cycle, thereby rendering increased knowhow for the practice of ARM. Consequently, real-world examples demonstrating SRLF deployment across governance levels will be beneficial to test application of this heuristic framework to develop it further. Currently, principles of the SRLF are being applied in two ARM case-study areas: South Africa, associated with implementation of the ecological Reserve, and in Australia, associated with environmental watering in the Murray-Darling Basin.

Responses to this article can be read online at: http://www.ecologyandsociety.org/issues/responses. $\mathrm{php} / 7303$

\begin{abstract}
Acknowledgments:
We thank Melissa Parsons for her comments on an earlier version of the manuscript, and two anonymous reviewers for their critical inputs. This work stems from several years of adaptive management research associated with South African National Parks, South African Water Research Commission, and the Inkomati Catchment Management Agency. Support and guidance by Kevin Rogers and Harry Biggs provided valuable impetus for this work over the years. An Australian government PhD scholarship allowed for further advancement and development of the work.
\end{abstract}

\section{LITERATURE CITED}

Ahl, V., and T. F. H. Allen. 1996. Hierarchy theory: a vision, vocabulary and epistemology. Columbia University Press, New York, New York, USA.

Allan, C., and G. H. Stankey. 2009. Synthesis of lessons. Pages 341-346 in C. Allan and G. H. Stankey, editors. Adaptive environmental management: a practitioner's guide. Springer, Collingwood, Australia. http://dx.doi.org/10.1007/978-1-4020-9632-7_19

Argyris, C., and D. Schon. 1978. Organizational learning: a theory of action perspective. Addison Wesley, Reading, Massachusetts, USA.

Barrett, G. W., J. D. Peles, and E. P. Odum. 1997. Transcending processes and the levels-of-organization concept. Bioscience 47:531-535. http://dx.doi.org/10.2307/1313121 
Biggs, H., C. Breen, R. Slotow, S. Freitag, and M. Hockings. 2011a. How assessment and reflection relate to more effective learning in adaptive management. Koedoe 53(2):Art1001. http:// dx.doi.org/10.4102/koedoe.v53i2.1001

Biggs, H., S. Ferreira, S. Freitag-Ronaldson, and R. Grant-Biggs. 2011b. Taking stock after a decade: Does the 'thresholds of potential concern' concept need a socio-ecological revamp? Koedoe 53(2):Art1002. http://dx.doi.org/10.4102/koedoe.v53i2.1002

Biggs, H., and K. H. Rogers. 2003. An adaptive system to link science, monitoring and management in practice. Pages 59-80 in $\mathrm{J}$. T. du Toit, K. H. Rogers, and H. C. Biggs, editors The Kruger experience: ecology and management of savanna heterogeneity. Island Press, Washington, D.C., USA.

Cundill, G., G. S. Cumming, D. Biggs, and C. Fabricius. 2012. Soft systems thinking and social learning for adaptive management. Conservation Biology 26:13-20. http://dx.doi. org/10.1111/j.1523-1739.2011.01755.X

Dollar, E. S. J., C. S. James, K. H. Rogers, and M. C. Thoms. 2007. A framework for interdisciplinary understanding of rivers as ecosystems. Geomorphology 89:147-162. http://dx.doi.org/10.1016/ j.geomorph.2006.07.022

Edwards, S. R. 2002. Foreward. Pages 93-103 in J. A. E. Oglethorpe, editor. Adaptive management: from theory to practice. International Union for Conservation of Nature, Gland, Switzerland.

Fabricius, C., and G. Cundill. 2014. Learning in adaptive management: insights from published practice. Ecology and Society 19(1): 29. http://dx.doi.org/10.5751/ES-06263-190129

Fazey, I., and L. Schultz. 2009. Adaptive people for adaptive management. Pages 323-338 in C. Allan and G. H. Stankey, editors. Adaptive environmental management: a practitioner's guide. Springer, Collingwood, Australia. http://dx.doi. org/10.1007/978-1-4020-9632-7 18

Folke, C., T. Hahn, P. Olsson, and J. Norberg. 2005. Adaptive governance of social-ecological systems. Annual Review of Environment and Resources 30:441-473. http://dx.doi.org/10.1146/ annurev.energy.30.050504.144511

Garmestani, A. S., C. R. Allen, and L. Gunderson. 2009. Panarchy: discontinuities reveal similarities in the dynamic system structure of ecological and social systems. Ecology and Society 14(1): 15. [online] URL: http://www.ecologyandsociety.org/ vol14/iss 1/art15/

Gregory, R., L. Failing, M. Harstone, G. Long, T. McDaniels, and D. Ohlson. 2012. Structured decision making: a practical guide to environmental management choices. Wiley-Blackwell, Chichester, UK. http://dx.doi.org/10.1002/9781444398557

Greig, L. A., D. R., Marmorek, C. Murray, and D. C. E. Robinson. 2013. Insight into enabling adaptive management. Ecology and Society 18(3): 24. http://dx.doi.org/10.5751/ES-05686-180324

Gunderson, L., and C. S. Holling, editors. 2002. Panarchy: understanding transformations in human and natural systems. Island Press, Washington, D.C., USA.
Gunderson, L., and S. S. Light. 2006. Adaptive management and adaptive governance in the Everglades ecosystem. Policy Sciences 39:323-334. http://dx.doi.org/10.1007/s11077-006-9027-2

Hargrove, R. 2002. Masterful coaching. Revised Edition. JosseyBass/Pfeiffer, Wiley, Sab Francisco, California, USA.

Herrfahrdt-Pahle, E. 2013. Integrated and adaptive governance of water resources: the case of South Africa. Regional Environmental Change 13:551-561. http://dx.doi.org/10.1007/ s10113-012-0322-5

Holling, C. S. 2001. Understanding the complexity in economic, ecological, and social systems. Ecosystems 4:390-405. http://dx. doi.org/10.1007/s10021-001-0101-5

Ison, R., and D. Watson. 2007. Illuminating the possibilities for social learning in the management of Scotland's water. Ecology and Society 12(1): 21. [online] URL: http://www.ecologyandsociety. org/vol12/iss1/art21/

Jabareen, Y. 2009. Building a conceptual framework: philosophy, definitions, and procedure. International Journal of Qualitative Methods 8:49-62.

Jiggins, J., and N. Röling. 2002. Adaptive management: potential and limitations for ecological governance of forests in a context of normative pluriformity. Pages 93-104 in J. A. E. Oglethorpe, editor. Adaptive management: from theory to practice. International Union for Conservation of Nature, Gland, Switzerland and Cambridge, UK.

Kingsford, R. T., and H. C. Biggs. 2012. Strategic adaptive management guidelines for effective conservation of freshwater ecosystems in and around protected areas of the world. International Union for Conservation of Nature WCPA Freshwater Taskforce, Australian Wetlands and Rivers Centre, Sydney, Australia.

Kolb, D. A. 1984. Experiential learning: experience as the source of learning and development. Prentice Hall, Englewood Cliffs, New Jersey, USA.

Kotliar, N. B., and J. A. Wiens. 1990. Multiple scales of patchiness and patch structure: a hierarchical framework for the study of heterogeneity. OIKOS 59:253-260. http://dx.doi.org/10.2307/3545542

Martin, J., M. C. Runge, J. D. Nichols, B. C. Lubow, and W. L. Kendall. 2009. Structured decision making as a conceptual framework to identify thresholds for conservation and management. Ecological Applications 19:1079-1090. http://dx. doi.org/10.1890/08-0255.1

McLoughlin, C. A., A. Deacon, H. Sithole, and T. Gyedu-Ababio. 2011b. History, rationale, and lessons learned: thresholds of potential concern in Kruger National Park river adaptive management. Koedoe 53(2):Art996. http://dx.doi.org/10.4102/ koedoe.v53i2.996

McLoughlin, C. A., J. MacKenzie, M. Rountree, and R. Grant. 2011a. Implementation of strategic adaptive management for freshwater protection under the South African national water policy. Water Research Commission Research Report No. 1797/1/11. WRC, Pretoria, South Africa. 
Mostert, E., C. Pahl-Wostl, Y. Rees, B. Searle, D. Tàbara, and J. Tippett. 2007. Social learning in European river-basin management: barriers and fostering mechanisms from 10 river basins. Ecology and Society 12(1): 19. [online] URL: http://www. ecologyandsociety.org/vol12/iss1/art19/

O’Neill, R. V., A. R. Johnson, and A. W. King. 1989. A hierarchical framework for the analysis of scale. Landscape Ecology 3:193-205. http://dx.doi.org/10.1007/BF00131538

Pahl-Wostl, C. 2008. Requirements for adaptive water management. Pages 1-22 in C. Pahl-Wostl, P. Kabat, and J. Moltgen, editors. Adaptive and integrated water management. Coping with complexity and uncertainty, Springer Verlag, Heidelberg, Germany.

Pahl-Wostl, C. 2009. A conceptual framework for analysing adaptive capacity and multi-level learning processes in resource governance regimes. Global Environmental Change 19:354-365. http://dx.doi.org/10.1016/j.gloenvcha.2009.06.001

Pahl-Wostl, C., G. Becker, C. Knieper, and J. Sendzimir. 2013. How multilevel societal learning processes facilitate transformative change: a comparative case-study analysis on flood management. Ecology and Society 18(4): 58. http://dx.doi.org/10.5751/ ES-05779-180458

Pahl-Wostl, C., M. Craps, A. Dewulf, E. Mostert, D. Tabara, and T. Taillieu. 2007a. Social learning and water resources management. Ecology and Society 12(2): 5. [online] URL: http:// www.ecologyandsociety.org/vol12/iss2/art5/

Pahl-Wostl, C., P. Jeffrey, N. Isendahl, and M. Brugnach. $2011 a$. Maturing the new water management paradigm: progressing from aspiration to practice. Water Resources Management 25:837-856. http://dx.doi.org/10.1007/s11269-010-9729-2

Pahl-Wostl, C., J. Moltgen, E. Ebenhoh, G. Holtz. 2007b. The new water management and transition framework-state and development process. Pages 75-96 in C. Pahl-Wostl, P. Kabat, and J. Moltgen, editors. Adaptive and integrated water management. Coping with complexity and uncertainty, Springer Verlag, Heidelberg, Germany.

Pahl-Wostl, C., C. Nilsson, J. Gupta, and K. Tockner. 2011 . Societal learning needed to face the water challenge. Ambio 40:549-553. http://dx.doi.org/10.1007/s13280-011-0149-1

Parsons, M. E., and M. C. Thoms. 2007. Hierarchical patterns of physical-biological associations in river ecosystems. Geomorphology 89:127-146. http://dx.doi.org/10.1016/j.geomorph.2006.07.016

Peterson, D. L., and V. T. Parker. 1998. Ecological scale - theory and applications. Complexity in ecological systems. Columbia University Press, New York, New York, USA.

Pickett, S. T. A., J. Wu, and M. L. Cadenasso. 1999. Patch dynamics and the ecology of disturbed ground: a framework for synthesis. Pages 707-722 in L. R. Walker, editor. Ecosystems of the world: ecosystems of disturbed ground. Elsevier Science, Amsterdam, The Netherlands.

Pollard, S., and D. du Toit. 2007. Guidelines for strategic adaptive management: experiences from managing the rivers of the Kruger National Park. UNEP/GEF Project No. GF/2713-03-4679, EPP Project. International Union for Conservation of Nature, Gland, Switzerland.
Pollard, S., D. du Toit, and H. Biggs. 2011. River management under transformation: the emergence of strategic adaptive management of river systems in the Kruger National Park. Koedoe 53(2):Art1011. http://dx.doi.org/10.4102/koedoe.v54i1.1011

Pratt Miles, J. D. 2013. Designing collaborative processes for the adaptive management: four structures for multistakeholder collaboration. Ecology and Society 18(4): 5. http://dx.doi. org/10.5751/ES-05709-180405

Quinn, G. P., and M. J. Keough. 2002. Experimental design and data analysis for biologists. Cambridge University Press, New York, New York, USA. http://dx.doi.org/10.1017/CBO9780511806384

Rist, L., B. M. Campbell, and P. Frost. 2013b. Adaptive management: Where are we now? Environmental Conservation 40:5-18. http://dx.doi.org/10.1017/S0376892912000240

Rist, L., A. Felton, L. Samuelsson, C. Sandström, and O. Rosvall. 2013a. A new paradigm for adaptive management. Ecology and Society 18(4): 63. http://dx.doi.org/10.5751/ES-06183-180463

Rogers, K. H. 2003. Adopting a heterogeneity paradigm: implications for management of protected areas. Pages 41-58 in J. T. du Toit, K. H. Rogers and H. C. Biggs, editors. The Kruger experience: ecology and management of savanna heterogeneity. Island Press, Washington, D.C., USA.

Rogers, K. H., and H. Biggs. 1999. Integrating indicators, endpoints and value systems in the strategic management of the rivers of the Kruger National Park. Freshwater Biology 41:439-451. http://dx.doi.org/10.1046/j.1365-2427.1999.00441.X

Rogers, K. H., R. Luton, H. Biggs, R. Biggs, S. Blignaut, A. G. Choles, C. G. Palmer, and P. Tangwe. 2013. Fostering complexity thinking in action research for change in social-ecological systems. Ecology and Society 18(2): 31. http://dx.doi.org/10.5751/ ES-05330-180231

Rogers, K. H., D. Roux, and H. Biggs. 2000. Challenges for catchment management agencies: lessons from bureaucracies, business and resource management. Water SA 26:505-512.

Roux, D. J., and L. C. Foxcroft. 2011. The development and application of strategic adaptive management within South African National Parks. Koedoe 53(2):Art1049. http://dx.doi. org/10.4102/koedoe.v54i1.1049

Scarlett, L. 2013. Collaborative adaptive management: challenges and opportunities. Ecology and Society 18(3): 26. http://dx.doi. org/10.5751/ES-05762-180326

Stankey, G. H., R. N. Clark, and B. T. Bormann. 2005. Adaptive management of natural resources: theory, concepts and management institutions. General Technical Report PNWGTR-654, U.S. Forest Service, Pacific Northwest Research Station, Portland, Oregon, USA.

Susskind, L., A. E. Camacho, and T. Schenk. 2012. A critical assessment of collaborative adaptive management in practice. Journal of Applied Ecology 49:47-51. http://dx.doi.org/10.1111/ j.1365-2664.2011.02070.x

Swemmer, L. K., and S. Taljaard. 2011. SANParks, people and adaptive management: understanding a diverse field of practice during changing times. Koedoe 53(2):Art1017. http://dx.doi. org/10.4102/koedoe.v54i1.1017 
Thoms, M. C., and M. Parsons. 2002. Ecogeomorphology: an interdisciplinary approach to river science. International Association of Hydrological Sciences 27:113-119.

van Wilgen, B. W., and H. C. Biggs. 2011. A critical assessment of adaptive ecosystem management in a large savannah protected area in South Africa. Biological Conservation 144:1179-1187. http://dx.doi.org/10.1016/j.biocon.2010.05.006

Walker, B., and D. Salt. 2012. Resilience practice: building capacity to absorb disturbance and maintain function. Island Press, Washington, D.C., USA. http://dx.doi.org/10.5822/978-1-61091-231-0

Wenger, E. 1998. Communities of practice: learning, meaning, and identity. Cambridge University Press, Cambridge, UK. http://dx. doi.org/10.1017/CBO9780511803932

Westgate, M. 2013. The evidence on adaptive management: Everybody is talking about it but how many are actually doing it? Decision Point 74:12-13.

Wiliams, B. K., and E. D. Brown. 2014. Adaptive management: from more talk to real action. Environmental Management 53:465-479. http://dx.doi.org/10.1007/s00267-013-0205-7 